\title{
Strategic Growth of Everything-as-a-Service (XaaS) Business Model Transformation
}

\author{
Venkata Naga Satya Surendra Chimakurthi
}

Solutions Architect, CDBDX-Platforms-DAM (Digital Asset Management), Cognizant Technology Solutions, Dallas, USA

*Corresponding Contact:

Email: chvnssurendra@gmail.com

\begin{abstract}
The study presents the XaaS architecture and explores how this business model has strategically developed and how it has revolutionized the whole business industry. The study indicates how this particular business model allows companies to enhance the range of advantages of Internet Cloud model applications, particularly when it deals with process of media processing and customization of users. Its huge benefits with negligible disadvantages are mentioned as part of the presented research. This study will help to understand the services of XaaS model, challenges experiencing by it and its future opportunities. This will also assists new scholars of field to build a better understanding and better prospects regarding XaaS in future.
\end{abstract}

Key words:

XaaS, Internet cloud, Business model

\section{INTRODUCTION}

Anything as a service or XaaS defines a standard category of computer-related cloud and remote access. It sees a large number of products, tools, and technologies now being delivered to users as an online service. It recognizes the large number of products, tools and technologies that retailers now offer to users as a network service - usually online - rather than providing a place or site within a business. Because XaaS stands for "anything as a service," the list of examples is endless. Many types of IT services or services are now delivered this way. In general, there are three categories of cloud computing models: software as a service (SaaS), platform as a service (PaaS), and infrastructure as a service (IaaS). Apart from these categories, there are other examples such as disaster recovery as a service (DRaaS), communication as a service (CaaS), network as a service (NaaS), database as a service (DBaaS), storage as a service (STAaS), desktop as a service (DaaS), and monitoring as a service (MaaS). Other examples of emerging industries include marketing as a service and health care as a service. 
The way companies do their work was permanently altered by public health needs during the COVID-19 violence. As companies switched to working from home (WFH) model, they sometimes had to switch quickly to cloud-based services so employees could access applications anywhere. That experience demonstrated to many the power of cloud-based services. Therefore, in the coming years, XaaS is expected to continue to grow. If you are going to explore all the options that can help them to continue their success, you should consider these services at least as a possibility. Using the questions in the list above, you can make informed decisions about whether XaaS can work well for your company and meet the needs of your business (Vuong \& Tran, 2021).

\section{LITERATURE REVIEW}

Researchers have reported that XaaS can reduce data warehousing problems as well as problems with the use of cloud-based environments and thus address the problem of vendor locking (Chimakurthi, 2021b). In addition, it simplifies the decision-making process using a framework designed to move cloud-enabled applications from one cloud to another and provides basic ways to help organizations find the best cloud provider in the market place (Azam et al., 2021). One study said that XaaS provides more efficient network performance and its ability to achieve flexible behavior for service providers and demanders (Bano et al., 2019).

Research conducted to analyze the factors that contribute to the success of XaaS has revealed that flexibility in the XaaS economy is only limited to accessible technologies. Providers of technology service have realized that their products can be re-packaged as services, which opens the door for many companies in all vertical areas to transform into the XaaS economy. Manufacturers can now monitor product usage in real time, in order to quickly create new features and prevent product decline (Manavalan, 2019). Customer-focused vendors can quickly introduce new products and collect data on how customers, where, and when to use products. In their view, based on a survey of 32 successful companies, every company is able to respond and deliver quality customer service. Savvy companies that take advantage of the data that comes with the XaaS economy are able to anticipate customer needs, improve customer and product loyalty. Companies should keep in mind that because of technology, there are no restrictions on how people register and spend money (Duan, 2012).

Researchers also report that Xaas helps different companies to understand the needs of their customers, and to meet them more effectively than ever before. It also generates demand of their products and services depending on expected trend, browsing behaviour, and past shopping history. In addition, make strong links with existing customers with technology, real-time statistics, and closed opportunities like responses, review sites, surveys, questioners, and different social media platforms. At present, most business owners are aware of the value and value of creating backups of the systems at regular basis. The present world is quite unpredictable, and businesses have learned to simply expect almost everything from massive storms to extreme human violence (Bittman et al., 2008). According to market-based research, no matter what happens to a business's neck in the woods, being a XaaS user depicts managers may ensure that their data is securely backed up. After the mishap like a fire or any such disaster, all company data stored in the Clouds can be completely obtained quickly and successfully restored within an hour (Paasivaara et al., 2014). 
Recent research highlights the importance of XaaS during the epidemic. Researchers have reported that during the epidemic, long-distance work became quite commonplace, with many companies authorizing permanent models of long-distance work. Many businesses have realized that their IT infrastructure is inadequate. The industry has seen great acceleration in acquiring 'Anything as a Service' (XaaS). XaaS is a new paradigm that forces digital transformation to take over the functions of XaaS. The main goal of the XaaS model is to increase customer value, allowing customers to move from capital expenditure (Capex) to unpredictable operating costs (Opex) (Grigorescu \& Mocanu, 2020). Researchers predict the future of XaaS and say that with the ever-changing digital world, businesses are preparing to seek new business models, flexible technology platforms, and the world is in tune with the artificial intelligence (AI) and internet of things (IoT) (Ragi et al., 2021; Manavalan \& Ganapathy, 2014). Future of XaaS is secure and will run the business and control the future of cloud computing (Chan, 2001).

\section{Changes in Business Strategies}

Expectations of economic growth have plummeted; according to PwC's 2020 CEO Survey, $53 \%$ of US CEOs expects global economic growth rates to decline next year. Retrenchment has become commonplace as managers seek strategies to return to normalcy and growth. But how does it drive growth in a stagnant economy?

Adopting a business model based on digital technology is one way to promote biodiversity (Chimakurthi, 2020; Manavalan, 2014). Anything-as-a-Service (XaaS) business models help your organization switch from a product-based approach to a service or outcome-based approach, bring improved value to the customer and improve revenue. All-as-a-Service (XaaS) is the name of a cloud computing for multiple services as well as applications that are accessed where they are needed online instead of locally available. In the past, digital marketing often considered investing just a portion of hard-earned money in computer and hardware programs. This takes up huge space on the premises and should be favored, maintained and constantly improved, leading to inefficient working. Since the start of the service growth and revolution, however, all that has altered. Companies of all sizes can now apply cloud-based architecture to fulfill their entire needs of technology. This changes the methods of doing business, and this performs very well in helping businesses to grow and grow (Hart, 2010).

\section{Was this Transformation Necessary?}

Hardware products of manufacturing companies have been greatly improved. The proliferation of digital technology strengthens the integration of products and all related services with respect to mixed offerings that combine smart products with intelligent services. It is believed, if manufacturing companies can monitor all the appropriate performance indicators and measures for such mixed-use packages, they are on the peak of continuing to transform the business (Clark et al., 2002).

In this phase, a number of products as well as services combine to formulate a single service offering. This service provides customers a chance to use the product while the supply chain guarantees the performance of the product. Product-as-a-Service is the name of this kind of donation. Different industry based applications of this idea have come into being, including Lightning-as-a-Service or Windpower-as-a-Service. These donations, in a broader context, are applied under All-as-a-Service (XaaS). Few manufacturing companies, however, offer XaaS, let alone the count of economically successful businesses in this endeavor. In contrast, 
software vendors demonstrate a resilient transition from selling local solutions for providing Software-as-a-Service (SaaS). For this purpose, the software companies need to reorganize their services. Beyond the just accepting a new model for their business, upgrading to XaaS was a business strategy for different software companies incorporating key organizational changes and new business model shown in figure 1 (Hills, 1996).
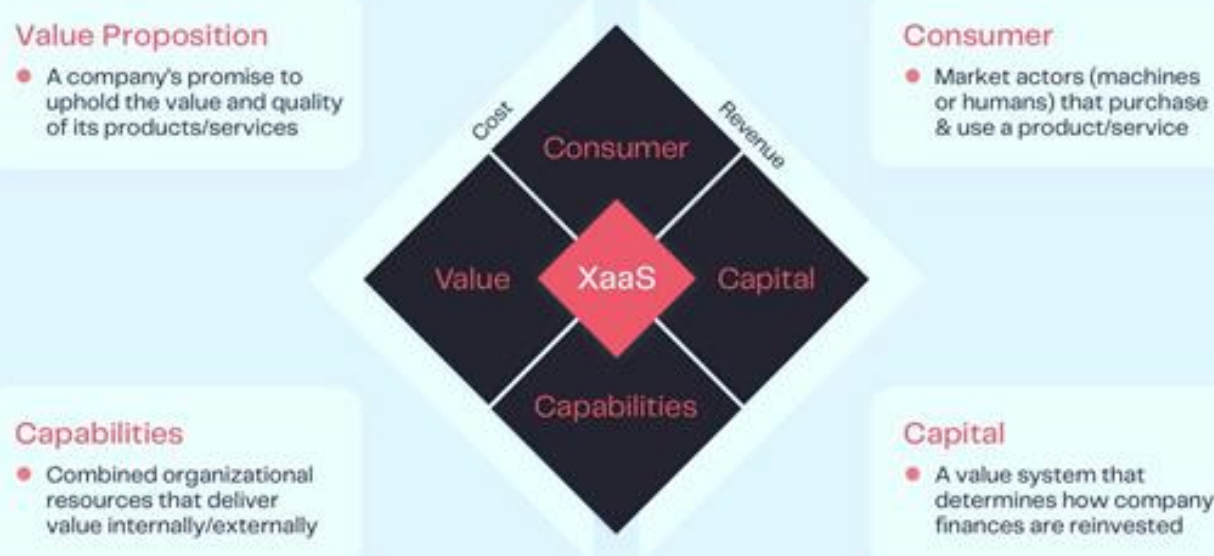

Capital

- A value system that determines how company finances are reinvested

Figure 1: New business model

\section{Did XaAS do Really Well?}

All-as-a-Service transforms the business model into a whole industry driven by their need to do more with less. Analysts predict that the global XaaS market will grow at a CAGR of more than $38 \%$ by 2020 . One of the key features of XaaS is the transition to an operating costs industry (OPEX) to manage IT infrastructure and reduce costs. Each payment model allows businesses to save on the huge costs required to build and manage buildings using internal resources. Also, the fact that XaaS brings a huge network of technologies and services through a single vendor network frees businesses from entering into multiple contracts with multiple vendors. Increasing flexibility and freedom of choice make XaaS attractive to businesses, small and large (Ganapathy, 2020).

The transformation of enterprise IT into the latest trends such as data center recognition and network optimization has brought additional demand for XaaS offering high levels of flexibility and smooth delivery options at an affordable price. Businesses are increasingly turning to server design, virtualization, and networking as part of their network integration strategy and cost savings. The XaaS approach frees the internal team from managing securityrelated risks, backup copy, and technical updates while also improving their disaster recovery (DR) capabilities. The service provider assumes responsibility for maintaining and updating the infrastructure under a special monthly package. Utilizing this technology has brought about a significant reduction in previous IT investments (Bano et al., 2019).

\section{TransferRing Storage-AS-A-SERVICE}

Storage-as-a-service (StaaS) is one of the fastest growing phase of XaaS, expected to grow by $40 \%$ by 2020 , according to reports. This is not surprising given the dramatic growth of data across all sectors of the industry over the past few years. Informal data lying on closed 
asset infrastructure brings additional storage concerns. This consistent structure prevents applications that are critical to performing their functions effectively. These data repositories need to be converted into structured storage objects that other forums and applications can use to generate meaningful business information. XaaS Market is evolving to deliver a content solution like Service to help businesses configure these databases and improve application performance. It also allows businesses to build storage infrastructure that can intelligently distribute resources across multiple domains.

The system provides high volume cloud storage in the central hub as well as cached storage in the building, thus reducing the load on the final storage area (Chimakurthi, 2021a). With the flexibility of resource allocation, storage systems separate workload between different layers, thus improving storage and performance while minimizing delays even during high load. The only investment in the area would be a small standard box built for storage. The as-a-Service model therefore brings the minimum storage space and ensures $100 \%$ availability at an affordable price (Qadir et al., 2016).

\section{IOT-AS-A-SERVICE In AnALYTICS Era}

Data analysis emerges as an opportunity to obtain relevant data and gain market segmentation through effective data use. Data grows at an unprecedented rate; much of that growth is due to IoT. Data generated from a large network of sensors and highly connected devices brings a new set of management challenges to business storage. IoT-as-a-Service gains value in this context as it addresses the data management challenges associated with advanced networks, which later help improve efficiency and customer experience. For example, Rail-as-a-Service- IoT-as-a-Service extension transforms the transport environment in Europe and the UK This new model combines IoT capabilities and big data to guide its overall performance. The self-assessment capabilities gained by the train system help to avoid delays and accidents, effectively bring about significant savings on CAPEX and OPEX railways and also enhance customer satisfaction (Deng et al., 2019).

\section{Challenges of Data Import and Data Lake-AS-A-Service}

Broadcasting various file sources on Hadoop has been another concern associated with traditional data import technology. Organizations today need a flexible and scalable way in which they can access large amounts of data from thousands of different information to Hadoop. With Data Lake-as-a-Service, organizations benefit from the automated data entry method, based on a template that brings the flexibility and flexibility needed in today's dynamic data environment (Hossen et al., 2021). The service helps eliminate manual errors related to strict coding data import processes. Automation also brings complex analytical skills when capturing new data (Beheshti et al., 2020).

\section{XaAs and General Data Protection Act}

In order to stay competitive in today's growing cloud-driven, data-driven market, companies must also protect asset data and use it to expand new data sources to identify new business opportunities. Businesses need more cached copy today than ever before because of the ever-changing nature of the security threat posed by unreliable features of the information age. In addition, in many states, companies are bound by rules that require the maintenance of customer data for a number of years in order to comply with the law. Traditional solutions for data protection do not provide the flexibility and robustness 
needed to achieve these goals. They also invite huge costs of making a backup copy and storage and often fail in terms of disaster recovery (DR) capabilities. Data Protection-as-aService (DPaaS) is a new service that empowers organizations to convert asset data into a secure, application-based system (Studihradová, 2018).

\section{MOVING FROM SAAS TO XAAS}

SaaS has been around for many years since the advent of cloud computing. SaaS transformed the software and IT industry in a significant way as it provided digital communication between the end user and its service provider. With more products and services connected digitally, XaaS is a much newer way to register. Importantly, XaaS provides businesses with greater flexibility, flexibility, and versatility in their existing design. A comparison of SaaS and XaaS is given in figure 2 (Anding, 2010).

SaaS

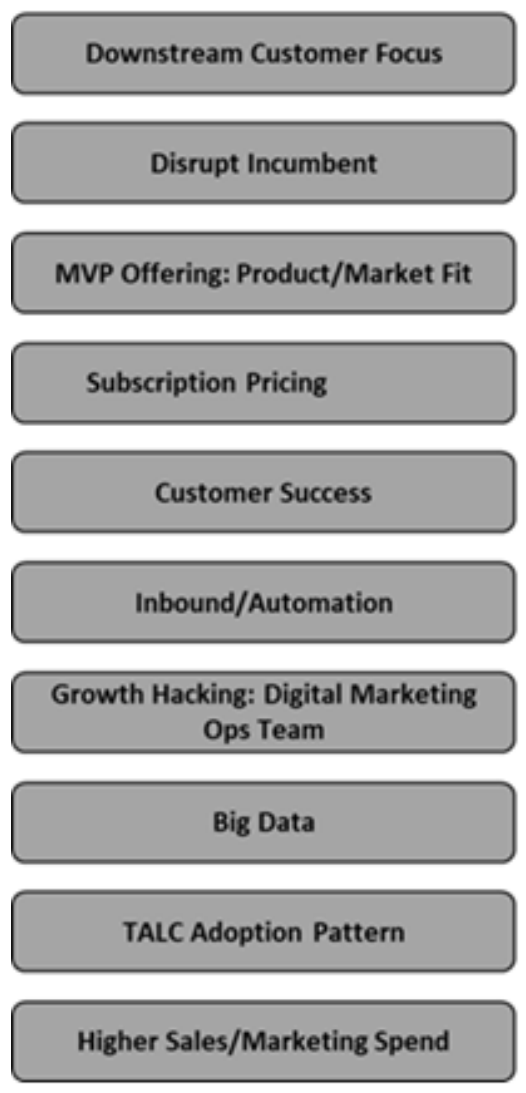

XaaS



Market Hacking: BizDevOps Team

Big Signals

Lower Sales/Marketing Support

Figure 2: Comparison of SaaS and XaaS

\section{XAAS MODEL}

Initially, companies used software as a service (SaaS). Then infrastructure like service (IaaS), monitoring (MaaS), platforms (PaaS) and communication (CaaS), came into existence. With passage of time, the combination of all these services to create a single and comprehensive 
option generates "everything as a service," currently named as XaaS. This is an effective as strategic plan, which, by opinion of Deloitte Insights, has started to modify many of the more effective business models (Perera et al., 2014)(figure 3).

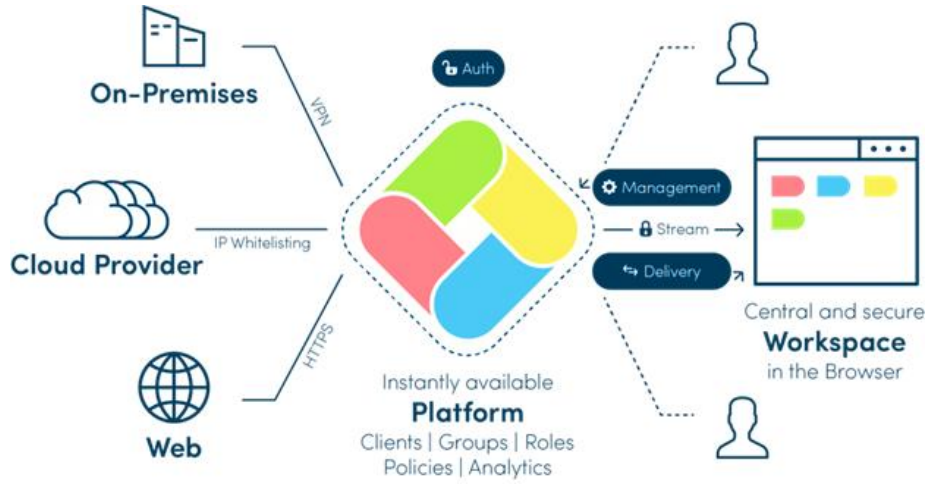

Figure 3: XaaS model

\section{What XaaS Involves}

It's okay and nice to state that XaaS covers "everything", but what truly does it all explains? First, this is not restricted to technology, and what started as a redesign of systems of legacy has expanded to enhance business efficiency, client engagement, and staff management through innovative, updated techniques. It also redefines many prime objectives of modernization because rather than having a variety of applications that work for monsters, business can set it up as a horizontal set of services available across the borders of the organization. That means the appropriate application programming interfaces (APIs) can be applied by multiple departments in the business, among many other items. For instance, companies may use a customer service module enabling the sales team to identify past customer relation with company. The similar module required to be applied by IT department to handle the service calls, as well as purchasing department to deal with popular suppliers (Bruneliere et al., 2018).

\section{Advantages of XaaS}

Companies benefit the most from using Xaas in various ways as it has multiple applications shown in figure 4.

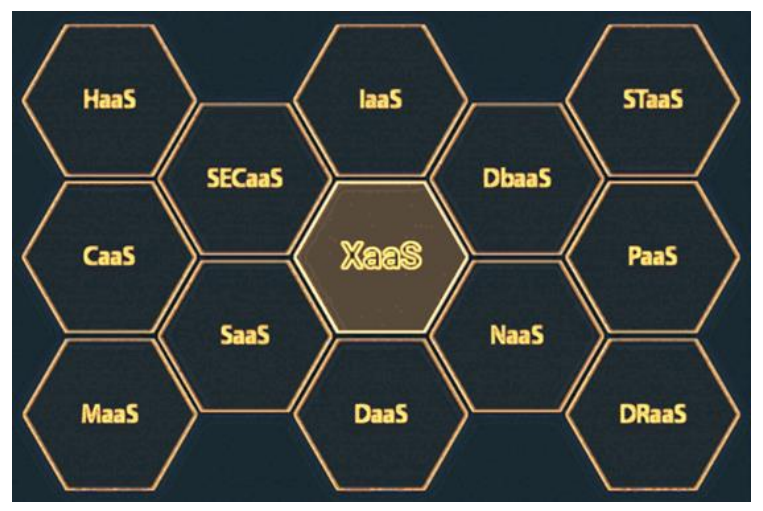

Figure 4: Applications of XaaS 
Its major benefits are listed below,

1. Financial Performance: Companies can earn huge savings without investing in various software programs. Moreover, from a hardware perspective, they not only keep them away from purchasing costly servers and storage tools, but now no need to spend money.

2. Improved Production: In 2014, the mobile network downtime lasted an average of 32 seconds per service annually. For business-class solutions it could add more than 526 minutes per annum, making estimated money of around $\$ 11,000$ per server.

3. Strong Cybersecurity: Around 70\% of hackers usually attack targeting small companies, $60 \%$ shut down in less than a year after such violations. Such threats put internet security at the top of the list of things you should have for many businesses. Cybercriminals have knowledge of the fact that these businesses are quite easy targets, in part as they expect weak protections due to financial limitations, as well as easy reach to client data and various other precious assets.

4. More Speed: One of the significant advantages of Xaas models in business is indeed the capability to be quicker as well as the flexible. Around $75 \%$ of users felt that XaaS made them comfortable in working and faster to find better solutions (Ganapathy, 2020).

5. Proper Use of Data: Many business owners decide critically depending on their knowledge and instinct. This is not a good way to decide. However, particularly in recent times the better availability of data rates in the playgrounds and gives companies the similar access to reach business intelligence.

6. Lower Capex and Overheads: Each penny has its worth in any business, and XaaS make the entrepreneur able to decrease extra expenses and personnel costs. From an IT person maintaining in-house systems to the fullest of his ability, to a training supervisor who monitors delivery using spreadsheets or any other manual program, spending a lot of money on financial assets and fixed prices can be completely eliminated through simply subscribing the service (Al-Shara et al., 2018).

Table 1: Advantages and Disadvantages of XaaS

\begin{tabular}{|l|l|}
\hline Advantages & Disadvantages \\
\hline $\begin{array}{l}\text { - Fast and realize benefits, quick set up } \\
\text { and deployment }\end{array}$ & - Lack of control \\
- Lower up-front cost & $\begin{array}{l}\text { - Vendor drives upgrades and new feature } \\
\text { timelines }\end{array}$ \\
- Scalability and integration & - Security and data sovereignty concerns \\
- New releases (upgrades) & - Limited range of applications \\
- Accessibility & $\begin{array}{l}\text { - Connectivity requirement } \\
\text { - Performance concerns (speed, reliability, } \\
\text { support) }\end{array}$ \\
\hline
\end{tabular}

\section{Disadvantages of XaaS}

As every bright picture has a dark side, similarly despite huge benefits there are certain disadvantages associated with XaaS. While companies reap many benefits from using XaaS, they also experience some disadvantages, which are closely related to security concerns. Additionally, if services are only available online and the Internet service is interrupted, users may not be able to access them. 
Also, the level of service may be tarnished as these services become popular and more and more people use them. Applications running in virtual environments may face integration issues. And customers are losing control of their lives when things go wrong. Instead, they should rely on their service provider to fix the problems quickly. A short summary of advantages and disadvantages of XaaS is shown in table 1 (Bhattacharya, 2021).

\section{Transition ROI}

One thing companies considering when using XaaS should consider what it will take to move from their current system to XaaS. While the outcome may be improvement, a period of disruption may follow before that happens. Companies that want to make this type of decision should include a team that includes company leaders, IT professionals, and representatives from other departments.

Some questions to consider before making a change include:

- How long will it take to make this change?

- What mechanical changes will we need to make, if any?

- How open are team members to this change?

- What will be needed to train team members in the new system?

- What are the expected benefits of the new system? Are they in line with the company's goals and plans?

- What are some alternatives to this change?

Companies should carefully consider these questions before deciding whether these changes are worth the time, money, and effort required (Grois \& Hadar, 2011).

\section{Challenges to XaaS}

To be successful in the XaaS economy, companies need to rethink every aspect of their business model. Companies need to think beyond the present and develop real strategies that put them in the future of XaaS. To do this the company leaders must be prepared to ask tough questions about their business, goals, customers, and ability to transform.

- What software and platforms are needed to manage duplicate payments, subscriptions, and flexibility?

- What is the strategy for increasing the depth of available data? How will usage monitoring data be used to develop new products and service packages?

- What can be done to improve customer relationships and support? How will B2B and $\mathrm{B} 2 \mathrm{C}$ customers get a seamless feel?

- What tools are available to take advantage of third-party product offerings, specials, and extensions?

- What is the customer ride plan?

- Do the right people, processes, and technologies exist to ensure that customers are not overwhelmed by the decline in service, product availability, and satisfaction? What are the regression plans?

- How will data security and privacy concerns be addressed and questions about this answered?

- Is the company ready for speed, flexibility, and innovation? How will business processes change to ensure that transformation takes place?

- How can current products that are on offer be re-packaged as a service and charged with a subscription model? What changes need to be made in the short and long term? 
- What are the new product opportunities as a service?

- What do customers want today, tomorrow, and next year? (Paasivaara et al., 2014)

\section{Opportunities for XaaS}

Customer requirements for customized products and services make it possible for any company to succeed in the XaaS economy. Now more than ever, customers are embracing unique service offerings, flexible payment models, and new ways to use and access products. This translation into new and flexible opportunities for investment companies that focus on expanding their XaaS and subscription-based products and service offerings:

- Quick Time to Go to Market. According to a study from Deloitte Insights, $75 \%$ of companies say that the XaaS model makes it easier to bring new products and services to market faster.

- Improved Production. Specialized tools, platforms, and software solutions are available for companies operating within the XaaS economy. These cloud-based solutions are designed to improve data, process processes, and provide information that translates into improved customer satisfaction.

- Use Big Data. Now, companies can develop data from millions of jobs. This data tells companies which products are effective, how customers use the products, and identify gaps in performance.

- New Product and Service Opportunities. Companies are no longer closed to traditional sales and business models. Customers acknowledge the non-actual ownership of the product and instead pay for access to it as a service.

- Confirmed Product and Customer Loyalty. When XaaS delivery is done well, customer and product loyalty increases. People want to develop lasting relationships with businesses - companies that respond to customer needs and use their data appropriately can increase credibility (Chang et al., 2017).

A summary of its opportunities is given in figure 5 .

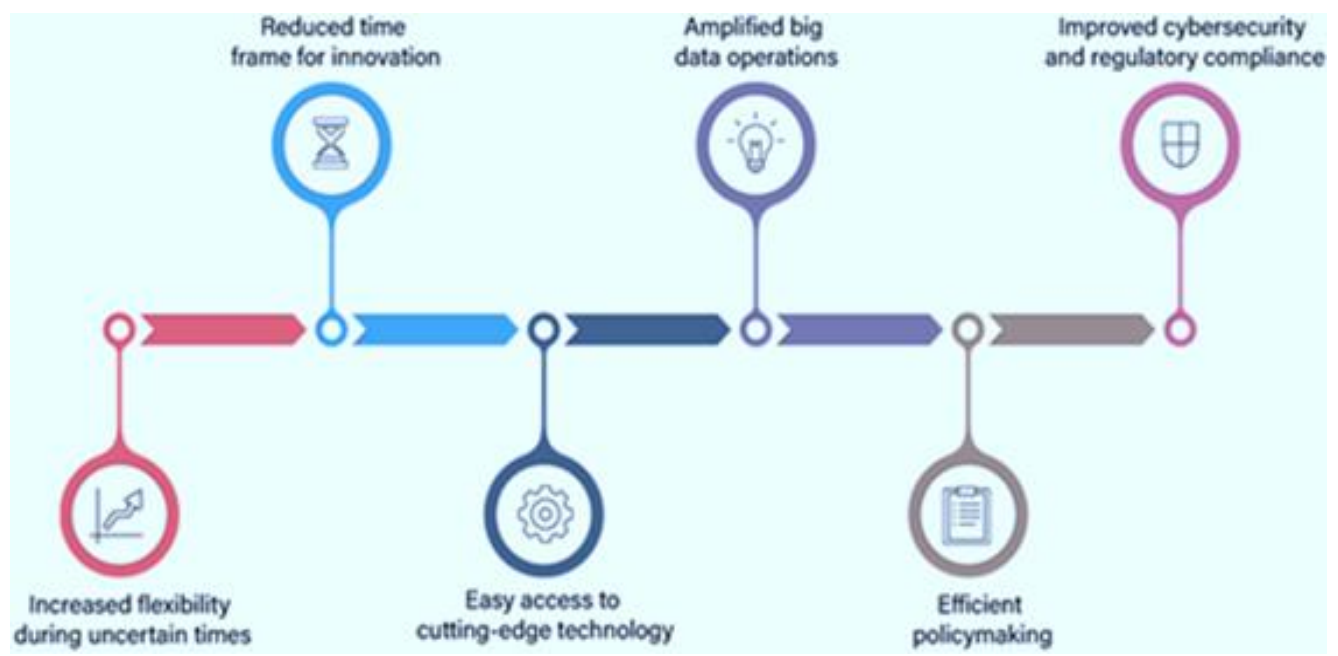

Figure 5: Future opportunities of XaaS 


\section{CONCLUSION}

Any business intended to grow or develop will get huge benefits from easy access to advanced IT technology and growing opportunities presented by Business Cloud services. Improve the performance of corporate systems, present better solutions, adjust ROI, manage downtime, enhance productivity, and get an idea that how the latest cloud opportunities can assist to innovate businesses. If not something exceptional, applying the XaaS solution reduces major cybersecurity threats, this alone is quite enough for any company or business to consider it as the model to adopt. Though it is experiencing a few challenges but researchers believe that future belongs to XaaS.

\section{REFERENCES}

Al-Shara, Z., Alvares, F., Bruneliere, H., Lejeune, J., Prud'Homme, C., Thomas Ledoux, T. (2018). CoMe4ACloud: An end-to-end framework for autonomic Cloud systems. Future Generation Computer Systems, 86, 339-354. https://doi.org/10.1016/j.future.2018.03.039.

Anding, M. (2010). SaaS: A Love-Hate Relationship for Enterprise Software Vendors. In: Benlian A., Hess T., Buxmann P. (eds) Software-as-a-Service. Gabler, 43-56. https://doi.org/10.1007/978$\underline{3-8349-8731-0 \quad 4}$

Azam, M. A., Mittelmann, H. D., \& Ragi, S. (2021). UAV Formation Shape Control via Decentralized Markov Decision Processes. Algorithms, 14(3), 91. https://doi.org/10.3390/a14030091

Bano, M., Qureshi, U. A., Rais, R. N. B., Tufail, M., and Qayyum, A. (2019). Miracle: An Agile Colocation Platform for Enabling XaaS Cloud Architecture. 2019 19th IEEE/ACM International Symposium on Cluster, Cloud and Grid Computing (CCGRID), 604-610, https://doi.org/10.1109/CCGRID.2019.00078

Beheshti, A., Benatallah, B., Sheng, Q. Z., \& Schiliro, F. (2020). Intelligent knowledge lakes: the age of Artificial Intelligence and big data. In L. H. U, J. Yang, Y. Cai, K. Karlapalem, A. Liu, \& X. Huang (Eds.), Web Information Systems Engineering: WISE 2019 Workshop, Demo, and Tutorial, Revised Selected Papers (pp. 24-34). Springer Nature. https:/ /doi.org/10.1007/978-981-15-3281-8_3

Bhattacharya, S. (2021). XaaS: Everything-as-a-Service - The Lean and Agile Approach to Business Growth. Pages: 1-436. https://doi.org/10.1142/11817

Bittman, T., Cearley, D., Plummer, D., Austin, T., Smith, D. (2008). Cloud computing: Defining and describing an emerging phenomenon. Gartner Research, 1-9.

Bruneliere, H., Al-Shara, Z., Alvares, F., Lejeune, J. and Ledoux, T. (2018). A Model-based Architecture for Autonomic and Heterogeneous Cloud Systems. In Proceedings of the 8th International Conference on Cloud Computing and Services Science - CLOSER, 201-212. https://dx.doi.org/10.5220/0006773002010212

Chan, J. B. L. (2001). The Technological Game: How Information Technology is Transforming Police Practice. Criminal Justice, 1(2), 139-159. https:/ / doi.org/10.1177/1466802501001002001

Chang, Z., Zhou, Z., Zhou, S., Chen, T. and Ristaniemi, T. (2018). Towards Service-Oriented 5G: Virtualizing the Networks for Everything-as-a-Service. IEEE Access, 6, 1480-1489, https://doi.org/10.1109/ACCESS.2017.2779170

Chimakurthi, V. N. S. S. (2020). Digital Asset Management in the Communication of Product Promotional Activities. Asian Business Review, 10(3), 177-186. https://doi.org/10.18034/abr.v10i3.587

Chimakurthi, V. N. S. S. (2021a). An Optimal Cloud Based Electric Vehicle Charging System. Asia Pacific Journal of Energy and Environment, 8(2), 39-48. https://doi.org/10.18034/apjee.v8i2.604

Chimakurthi, V. N. S. S. (2021b). The Future of Cloud Computing Amidst A Desperate Security Maze: The Impact Of COVID And The Future Challenges. Asian Journal of Humanity, Art and Literature, 8(2), 75-84. https://doi.org/10.18034/ajhal.v8i2.603 
Clark, M., Fletcher, P., Hanson, J. J., Irani, R., Waterhouse, M., Thelin, J. (2002).Web Services Business Strategies and Architectures. X, 346, https://doi.org/10.1007/978-1-4302-5356-3

Deng, D. J., Pang, A. C. \& Hanzo, L. (2019). Editorial: Recent Advances in IoT as a Service (IoTaas 2017). Mobile Netw Appl 24, 721-723, https://doi.org/10.1007/s11036-019-01247-1

Duan, Y. (2012). Value Modeling and Calculation for Everything as a Service (XaaS) Based on Reuse. 2012 13th ACIS International Conference on Software Engineering, Artificial Intelligence, Networking and Parallel/Distributed Computing, 162-167, https://doi.org/10.1109/SNPD.2012.30

Ganapathy, A. (2020). Everything-as-a-Service (XaaS) in the World of Technology and Trade. American Journal of Trade and Policy, 7(3), 91-98. https://doi.org/10.18034/ajtp.v7i3.555

Grigorescu, A., \& Nicolae, A. M. (2020). Teleworking perspectives for Romanian SMEs after the COVID-19 pandemic. Management Dynamics in the Knowledge Economy, 8(4), 383-399. http://dx.doi.org/10.2478/mdke-2020-0025

Grois, D. and Hadar, O. (2011). Complexity-aware adaptive spatial pre-processing for ROI scalable video coding with dynamic transition region. 2011 18th IEEE International Conference on Image Processing, 741-744, https://doi.org/10.1109/ICIP.2011.6116661

Hart, S. L. (2010). Capitalism at the crossroads: Next generation business strategies for a post-crisis world: FT Press.

Hills, M. (1996). Intranet business strategies: John Wiley \& Sons, Inc.

Hossen, M. A., Zahir, E., Ata-E-Rabbi, H. M., Azam, M. A., and Rahman, M. H. (2021). Developing a Mobile Automated Medical Assistant for Hospitals in Bangladesh. 2021 IEEE World AI IoT Congress (AIIoT), 0366-0372, https:/ / doi.org/10.1109/AIIoT52608.2021.9454236

Manavalan, M. (2014). Fast Model-based Protein Homology Discovery without Alignment. Asia Pacific Journal of Energy and Environment, 1(2), 169-184. https://doi.org/10.18034/apjee.v1i2.580

Manavalan, M. (2019). Using Fuzzy Equivalence Relations to Model Position Specificity in Sequence Kernels. Asian Journal of Applied Science and Engineering, 8, 51-64. Retrieved from https://upright.pub/index.php/ajase/article/view/42

Manavalan, M., \& Ganapathy, A. (2014). Reinforcement Learning in Robotics. Engineering International, 2(2), 113-124. https://doi.org/10.18034/ei.v2i2.572

Paasivaara, M., Behm, B., Lassenius, C. and Hallikainen, M. (2014). Towards Rapid Releases in LargeScale XaaS Development at Ericsson: A Case Study. 2014 IEEE 9th International Conference on Global Software Engineering, 16-25, https://doi.org/10.1109/ICGSE.2014.22

Peraković, D., Kuljanić, T., Musa, M. (2011). XaaS Services as Modern Infrastructure of ITS // Annals of $D A A A M$ for $2011 \mathcal{E}$ Proceedings of the 22nd International DAAAM Symposium. https://www.bib.irb.hr/565492

Perera, C., Zaslavsky, A., Christen, P., \& Georgakopoulos, D. (2014). Sensing as a service model for smart cities supported by internet of things. Transactions on emerging telecommunications technologies, 25(1), 81-93. https://arxiv.org/abs/1307.8198

Qadir, J., Ahmed, N., Yousaf, F. Z. \& Taqweem, A. (2016). Network as a service: the new vista of opportunities. https://arxiv.org/abs/1606.03060

Ragi, S., Rahman, M. H., Duckworth, J., Kalimuthu, J., Chundi P. and Gadhamshetty, V. (2021). Artificial Intelligence-driven Image Analysis of Bacterial Cells and Biofilms. ACM Transactions on Computational Biology and Bioinformatics, https://doi.org/10.1109/TCBB.2021.3138304

Studihradová, B. (2018). General Data Protection Regulation: Challenges for the Cloud. http://hdl.handle.net/20.500.11956/105850

Vuong, H. Q., \& Tran, T. M. (2021). The relationship between innovation and value creation by artificial intelligence: The case of the tourism industry in the Covid-19 pandemic. CEUR Workshop Proceedings, Da Nang, Vietnam. Vol 3026, Paper 9. http://ceur-ws.org/Vol-3026/paper9.pdf 